\title{
PARA UMA AVALIAÇÃO DE LARGA ESCALA MULTIDIMENSIONAL
}

ADILSON DALBEN LUANA COSTA ALMEIDA

\section{RESUMO}

Inserido no projeto de pesquisa financiado pelo Observatório da Educação - Coordenação de Aperfeiçoamento de Pessoal de Nivel Superior, "A qualidade da escola pública: um estudo longitudinal para a sustentação da responsabilização compartilhada", e partindo da observação de que a avaliação de larga escala atualmente praticada abarca um conjunto de objetivos menor do que aqueles da matriz de formação desenvolvida nas escolas, sendo esses demais objetivos também importantes para a formação dos alunos, o presente texto traz à discussão a necessidade de uma avaliação externa mais fiel ao trabalho desenvolvido nos estabelecimentos de ensino, que, para se consolidar como tal, não pode fugir à multidimensionalidade do objeto a ser avaliado. Discutem-se, assim, os processos de avaliação de larga escala, defendendo não se poder avaliar a aprendizagem dos estudantes e a qualidade ofertada pelas escolas sem a construção de uma avaliação multidimensional.

PALAVRAS-CHAVE AVALIAÇÃO DA EDUCAÇÃO • QUALIDADE DA EDUCAÇÃO • AVALIAÇÃO DA APRENDIZAgEM • AVALIAÇÃO INSTITUCIONAL. 


\section{RESUMEN}

Insertado en el proyecto de investigación financiado por el Observatorio de la Educación - Coordenação de Aperfeiçoamento de Pessoal de Nivel Superior, "A qualidade da escola pública: um estudo longitudinal para a sustentação da responsabilização compartilhada", y partiendo de la observación de que la evaluación de larga escala actualmente practicada abarca un conjunto de objetivos menor que aquellos de la matriz de formación desarrollada en las escuelas - aunque tales objetivos también sean importantes para la formación de los alumnos -, el presente texto discute la necesidad de una evaluación externa más fiel al trabajo desarrollado en los establecimientos de enseñanza que, para consolidarse como tal, no pueden dejar de lado la multidimensionalidad del objeto a evaluar. Se discuten los procesos de evaluación de larga escala y se defiende que no se puede evaluar el aprendizaje de los estudiantes y la calidad ofrecida por las escuelas sin construir una evaluación multidimensional.

PALABRAS CLAVE EVALUACIÓN DE LA EDUCACIÓN • CALIDAD DE LA EDUCACIÓN • EVALUACIÓN DEL APRENDIZAJE • EVALUACIÓN INSTITUCIONAL.

\section{ABSTRACT}

Inserted into the research project funded by the Center of education - Coordination for the Improvement of Higher Level Personnel, "The quality of public school: a longitudinal study for the sustainability of shared responsibility", andbased on the observation that the large-scale assessment currently practiced, a smaller set of goals than those of the training matrix developed in schools is involved. Although the other goals are also important for students' education, this article brings to discussion the need for an external and more truthful evaluation to the work developed in schools; that, in order to consolidate as such, cannot escape the multidimensionality of the object to be assessed. Therefore, the large-scale assessment processes are discussed, claiming that students' learning and the quality offered by schools cannot be assessed without constructing a multidimensional evaluation.

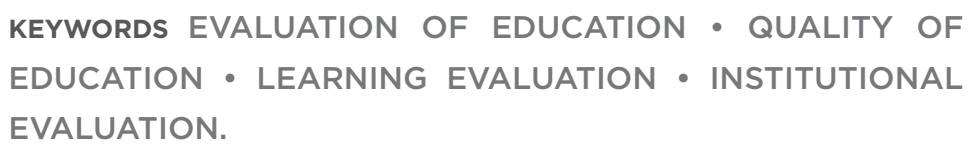




\section{INTRODUÇÃO}

Os processos de avaliação da aprendizagem sempre estiveram presentes nas trajetórias de escolarização no âmbito da sala de aula. Porém, desde a implementação das avaliações de larga escala, com o estabelecimento da correlação entre a aprendizagem dos alunos e a proficiência medida nos testes padronizados usados nessas avaliações, a atenção em relação à avaliação da aprendizagem atingiu outro patamar, pois passou a figurar como elemento central na análise e no financiamento dos sistemas educativos e de suas instituições escolares.

Acompanhando tal fenômeno, os estudos voltados aos processos de avaliação educacional têm se ampliado e aprofundado com o objetivo de analisar não só o fenômeno em si, no âmbito escolar e da sala de aula, mas também no contexto das políticas educacionais.

Interessados no que tem sido chamado de "reformas de Estado", que colocam a avaliação em seu centro, tomando-a como instrumento fundamental e motor das transformações (DIAS SOBRINHO, 2002), muitos estudos passaram a analisar 
os processos avaliativos, seus métodos e, também, dada sua natureza quantitativa, os modelos matemáticos e estatísticos aplicados.

Esses estudos ganham relevância sobretudo em tempos de execução do Plano Nacional de Educação (PNE) e delineamento do Sistema Nacional de Educação (SNE), que darão rumo à educação nacional e têm como parte importante de seu desenho as políticas de avaliação, principalmente quando é estabelecida uma associação entre a avaliação e o modelo estatal de educação, já que as análises explicitam as limitações técnicas e políticas comumente desconsideradas por seus propositores.

Entre essas limitações, a mais evidente delas se materializa com o fato de as atuais avaliações se proporem a medir a proficiência dos alunos em apenas duas ou três disciplinas escolares e tomar essa medida como representação de todo o trabalho realizado nas escolas e dos resultados dele decorrentes. Essa limitação pode ser traduzida em uma queixa bastante comum entre os profissionais da educação: "as avaliações não conseguem medir tudo o que a escola faz".

É importante, todavia, salientar que essa queixa não deixaria de existir com a ampliação do número de disciplinas avaliadas, tampouco com a ampliação dos conteúdos abordados pelas disciplinas já avaliadas, uma vez que a matriz curricular da escola é inevitavelmente muito mais ampla do que uma matriz de qualquer avaliação pode ser, da mesma maneira que a matriz de formação humana é mais ampla do que qualquer matriz curricular pode ser.

Reconhecendo essa inevitável restrição da matriz de avaliação em relação à matriz curricular e também os efeitos que os usos atualmente propostos da avaliação educacional têm no cotidiano escolar, a busca de uma proposta para a minimização dessa limitação é o ponto de análise do presente trabalho.

Essa proposta é também uma tentativa de resposta às provocações feitas por Betini (2009, p. 49) em sua tese de doutoramento, que teve como foco a avaliação institucional:

A prática da avaliação passa também pelo processo de democratização da escola. É imprescindível que haja o 
envolvimento e participação de todos os segmentos da escola: direção, professores, funcionários, alunos, pais, comunidade na elaboração de um plano de trabalho, no seu acompanhamento e na avaliação dos seus resultados. Esse procedimento dará à escola legitimação política à sua ação educativa. Como podemos perceber as três variáveis são inseparáveis quando se quer tornar o processo eficaz com resultados relevantes para o trabalho educativo. A quem serve o processo de avaliação educacional praticado hoje? Quais as suas origens? Como podemos utilizá-lo de modo positivo? Há que se buscar alternativas para a melhoria da qualidade social da escola por meio da avaliação. Ela é parte intrínseca do processo de ensino e aprendizagem.

O problema central não é, portanto, que essas avaliações tomem apenas uma parte dos objetivos da escola, pois foram elaboradas para tal, mas sim que, com essa limitação, seus resultados sejam utilizados como retrato da escola em âmbito geral e para fins meritocráticos, como se fossem o reflexo da totalidade do trabalho desenvolvido. As avaliações de larga escala deveriam ser parte da análise e não a principal medida utilizada na avaliação das instituições escolares.

Inserido na vertente quantitativa do projeto de pesquisa financiado pelo Observatório da Educação - Coordenação de Aperfeiçoamento de Pessoal de Nível Superior (CAPES), “A qualidade da escola pública: um estudo longitudinal para a sustentação da responsabilização compartilhada", que procura trazer à discussão a possibilidade de uma avaliação externa mais fiel ao trabalho desenvolvido nas escolas, o qual não pode fugir à multidimensionalidade do objeto a ser avaliado, o presente estudo procura trazer novos elementos para subsidiar os processos de avaliação sem deixar de colaborar para a orientação das políticas públicas.

\section{EM BUSCA DO RECONHECIMENTO DA NECESSIDADE DE UMA AVALIAÇÃO MULTIDIMENSIONAL}

Na busca de uma perspectiva mais abrangente para a avaliação, o foco de análise não deveria se restringir à mensuração 
dos conteúdos cognitivos, mas caberia também considerar quanto da proficiência adquirida pelo aluno se deve realmente ao trabalho realizado pela escola, afinal nem toda a aprendizagem dos alunos se deve ao ensino escolar, assim como nem tudo que a escola ensina é aprendido pelos alunos. As proficiências dos alunos medidas pelas atuais avaliações externas não dependem integralmente do trabalho da escola e dos professores. É necessário considerar os inúmeros fatores extraescolares que podem facilitar ou dificultar o aumento da proficiência (ALMEIDA, 2014).

O movimento vivenciado pelas escolas deixa claro que as avaliações externas têm provocado um grande reducionismo no processo pedagógico nelas desenvolvido, dada a associação provocada por esse processo avaliativo entre o trabalho da escola e o que é medido por meio de testes padronizados (FREITAS, 2011). Ou seja, ainda quando apresentado de maneira oculta, a preocupação em obter bons resultados concorre com a preocupação com uma formação mais ampla, distanciando a qualidade pretensamente medida nas avaliações de larga escala e a qualidade social que seria desejável às escolas.

De facto, falar-se de "qualidade em" implica sabermos, perfeitamente, o que se entende por qualidade, pois o modo como entendemos esse conceito condiciona a forma de "medir" e, portanto, de "avaliar" a sua concretização no terreno. (CABRITO, 2009, p. 181)

A avaliação deveria, ao contrário do que tem ocorrido no Brasil desde a década de 1990, considerar "a complexidade, a pluralidade, a polissemia, seja na perspectiva interna ou externa" (DIAS SOBRINHO, 2003, p. 173). Essa afirmação provoca um questionamento central: se as avaliações de larga escala não captam toda a aprendizagem possível nas escolas, o que a escola ensina para além do que é medido pelas avaliações externas?

Essa tem sido nossa pergunta central, pois explicita a limitação da medida das proficiências dos alunos (representando a aprendizagem desses alunos) como indicador da qualidade de ensino. Essa medida, inicialmente usada para orientar o trabalho pedagógico das escolas e o delineamento 
das políticas públicas para a melhoria das condições de ensino das instituições escolares, com o tempo passou a ser usada para a otimização da aplicação dos recursos nas escolas, ou seja, deslocou-se de uma finalidade pedagógica do uso dessa medida para uma finalidade econômica.

$\mathrm{O}$ atual uso das medidas remete ao conceito da "qualidade total", que é contraposto ao que é almejado em termos de melhoria das escolas, o que poderíamos chamar de "qualidade social", tal como sugere Betini (2009, p. 38).

Qual a qualidade necessária à educação brasileira? Quando focamos apenas resultados, estamos enfatizando a qualidade total. Por outro lado, quando buscamos a formação do aluno, que vai além da preparação técnica e científica, estamos falando da qualidade social, aquela que "tem profundos e diferenciados sentidos filosóficos, sociais e políticos" (DIAS SOBRINHO, 1995, p. 34). A cultura pode dar ao indivíduo uma visão de mundo; a preparação política está voltada para a sua participação como cidadão na sociedade civil; a preparação para uma profissão, para o trabalho, pode proporcionar às pessoas condições para se inserir na vida social.

As possíveis respostas a essa pergunta central, fundamentadas em uma matriz de formação mais ampla, têm sido consideradas elementos constitutivos para uma das possibilidades de definição de qualidade social.

Assim, a qualidade social, enquanto constructo que busca ampliar o conceito de qualidade pretensamente medido nas avaliações de larga escala, requer a compreensão de suas dimensões. Lembrando que qualidade é um conceito subjacente ao de avaliação, um delineamento que leva à qualidade social permitiria dar outro enfoque às avaliações externas.

Considerar outras dimensões de qualidade, tirando a exclusividade soberana da proficiência, traria grandes benefícios ao fornecer dados de outra natureza, sonegados nas avaliações atuais. Ainda que se ensaie considerar o Nível Socioeconômico (NSE) no delineamento das avaliações, ele não seria suficiente para solucionar o problema.

A influência do NSE sobre a proficiência permite explicar, e não justificar, melhores desempenhos em avaliações 
externas, porém o que se busca é compreender o que os diferentes estabelecimentos escolares fazem por seus alunos de forma a garantir que aprendam. Aprendizagem que não se limita, como anteriormente explicitado, ao que vem sendo medido nas avaliações externas em curso no Brasil e em boa parte do mundo, tampouco passível de medição, restringindo-se a dados quantitativos.

[...] a avaliação da qualidade em educação deve recorrer a uma bateria de indicadores de natureza quantitativa, mas também qualitativa, que pode, aliás, ser diferente de escola para escola. Quanto maior for o número daqueles indicadores de contexto, mais bem espelhada será a realidade que se pretende avaliar. (CABRITO, 2009, p. 197)

Como proposto por Dalben (2014), é necessário desenvolver processos avaliativos que considerem outros indicadores, já que as aprendizagens na escola são, essencialmente, multidimensionais. Ideia proposta por Hadji (1994, p. 29) quando elabora as questões:

Não significa isto que a operação de avaliação é fundamentalmente multidimensional e envolve um trabalho que se desdobra em múltiplos registros e em diferentes campos? Não seria então preciso caracterizar e descrever, não uma atividade, mas vários ângulos da avaliação?

Considerar essa complexidade para a construção dos processos de avaliação de larga escala exige a definição dessas outras aprendizagens esperadas. Ao assumir outras dimensões da aprendizagem nas escolas, superando as análises unidimensionais, passa a ser reconhecida a característica genuinamente multidimensional do processo educacional, como é representado, por exemplo, no Gráfico 1. 
GRÁFICO 1 - Exemplo de uma representação gráfica para os resultados de uma avaliação na qual foi utilizado um desenho multidimensional

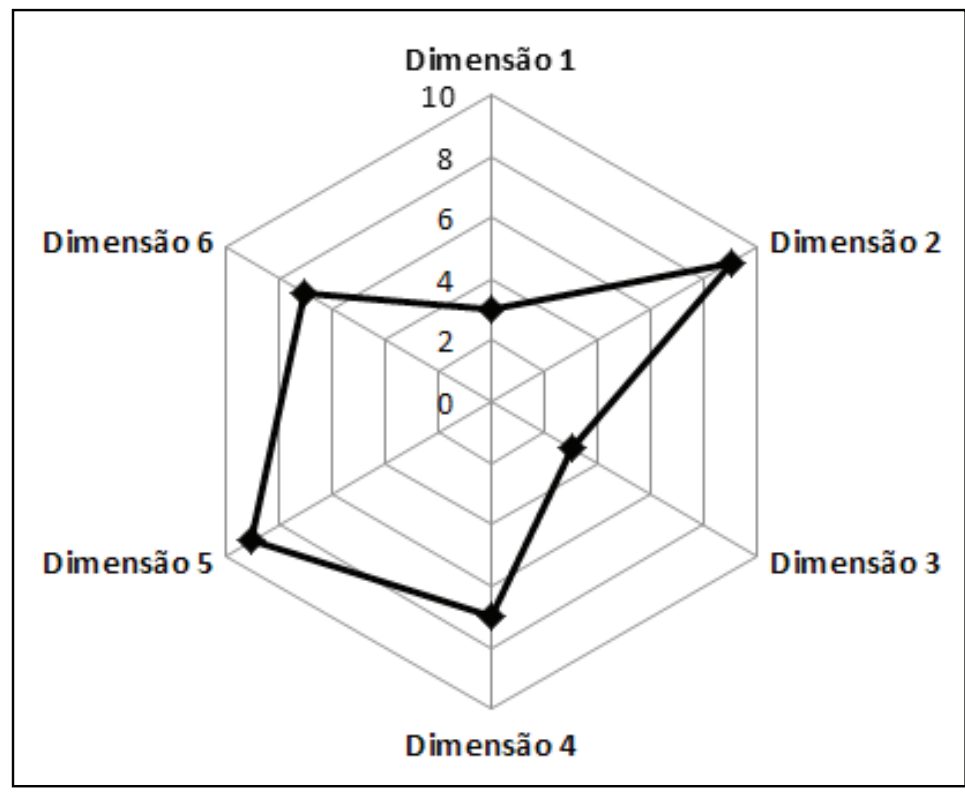

Fonte: Elaboração dos autores.

Uma das consequências diretas da avaliação multidimensional seria a impossibilidade de ranqueamento das diversas escolas, ação que ocorre quase intuitivamente quando a análise é unidimensional, mas impossível em uma análise multidimensional, como esquematizado na Figura 1. 
FIGURA 1 - Exemplo de possíveis representações gráficas para os resultados de uma avaliação, de acordo com o tipo de desenho utilizado

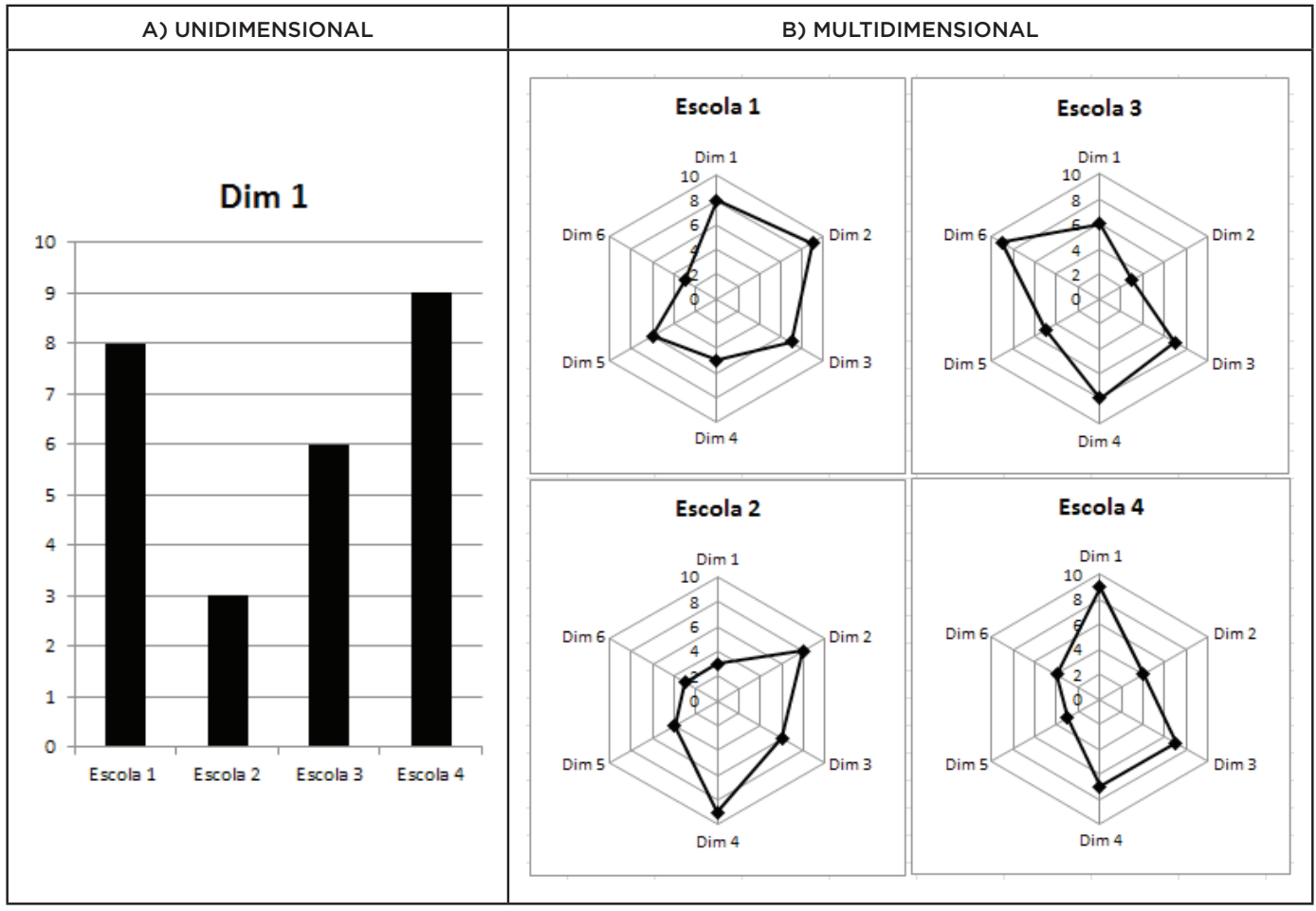

Fonte: Elaboração dos autores.

Enquanto na Figura 1-A o ranqueamento é possível por se tratar de uma avaliação unidimensional, quando são consideradas múltiplas dimensões, na Figura 1-B o processo é inviabilizado, uma vez que não é possível comparar os diferentes desempenhos em diferentes dimensões, e uma escola pode se sair melhor em uma dimensão da aprendizagem, mas apresentar um desempenho inferior em outra.

Essa proposta traria como benefício direto a possibilidade de que cada escola definisse quais dimensões são prioritárias em função do contexto no qual está inserida, sendo os processos de avaliação institucional idealmente propícios para esse movimento por permitirem, em um trabalho coletivo e com base nos dados, uma análise de seu desempenho e de definir as metas de curto, médio e longo prazo precisariam atingir para o aprimoramento de seu trabalho. Um exemplo dessa possibilidade seria o Gráfico 2. 
GRÁFICO 2 - Exemplo de uma possível representação gráfica para uma avaliação na qual foi utilizado um desenho multidimensional

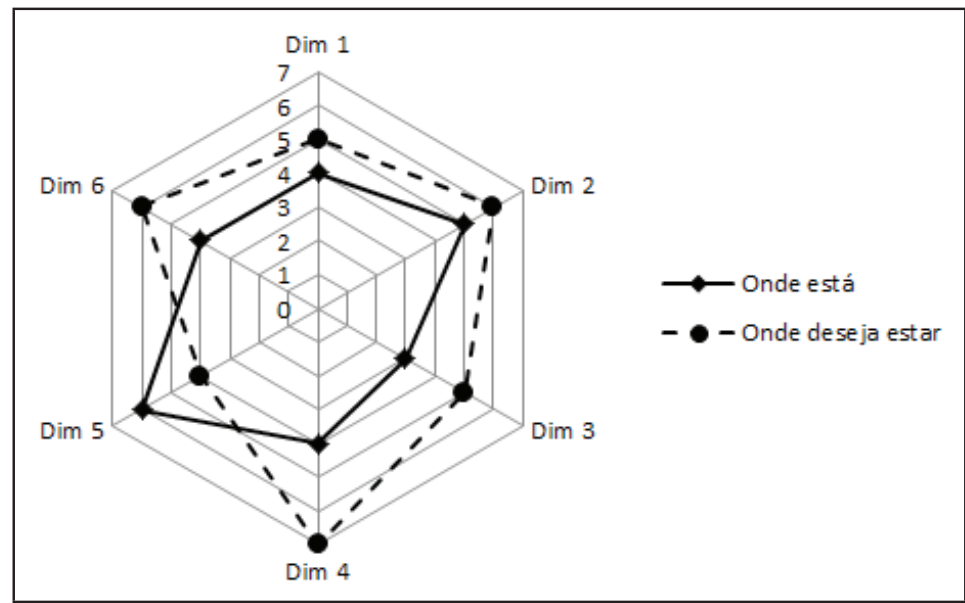

Fonte: Elaboração dos autores.

Essas dimensões, por sua natureza multidimensional, podem ser avaliadas e analisadas em diferentes momentos do ano letivo, considerando, além dos profissionais envolvidos, primordialmente, os alunos e seus familiares, por serem os principais beneficiários do sistema educacional e permitirem um viés de análise pouco explorado nos processos de avaliação, ainda que institucionais.

Nesse sentido, faz-se necessário que os processos de avaliação de larga escala e os resultados de suas medidas sejam ressignificados nas escolas em processos de avaliação interna, que permitam não apenas agregar novos dados a esses resultados, como também estabelecer metas e prioridades a serem perseguidas pela instituição.

Os processos de avaliação institucional que contam com a participação dos diversos segmentos da comunidade escolar podem ser uma possibilidade plausível para que as instituições se instrumentalizem e se organizem a fim de que o objetivo de uma melhor qualidade no ensino seja alcançado, sendo capaz de orientar as ações do coletivo escolar, analisando os resultados das avaliações externas e agregando a eles novos dados qualitativos de sua avaliação interna. Esse processo contribui para a reelaboração do Projeto Político-Pedagógico da escola, constituindo-se a partir 
desse movimento como um importante instrumento de aperfeiçoamento da instituição, já que pressupõe a participação de todos os sujeitos envolvidos (pais, alunos, comunidade, professores, gestores, funcionários, etc.).

Essa modalidade de avaliação na educação básica pode ser uma alternativa de trabalho, levando os agentes escolares à reflexão sobre os resultados das avaliações de larga escala, considerando a discussão sobre o aperfeiçoamento dos espaços educacionais e de seu próprio trabalho a partir dos resultados obtidos em suas diferentes dimensões. Esse último aspecto é corroborado no momento em que as avaliações possibilitam uma visão da multidimensionalidade da qualidade a ser construída na escola, não se restringindo a apenas uma dimensão do que deve ser aprendido pelo estudante em seu processo de formação.

Esses processos vivenciados na avaliação institucional fornecem, idealmente, dados importantes para a construção, reconstrução e melhoramento do Projeto Político-Pedagógico das escolas na medida em que se configuram como instrumento de reflexão acerca da própria escola, contemplando diversas fontes de informação e perspectivas de atuação.

Como bem lembra Fernandes (2002), “o projeto pedagógico é apontado como indicador de caminhos; e a avaliação como acompanhamento e redirecionamento da caminhada" (p. 59). Esse nível de avaliação configura uma prática necessariamente democrática, em que se vislumbra a formação de uma comunidade capaz de resolver suas questões e conflitos por meio de uma política de participação, autocrítica e autolegislação (LEITE, 2005).

A contribuição para esse processo de autoavaliação e utilização dos resultados encontrados por meio de avaliação de larga escala, considerando a multidimensionalidade aqui proposta, é certamente mais profícua, quando o uso meritocrático dos resultados é dificultado. Como diz Dias Sobrinho (2003, p. 173):

[...] é importante assegurar que a avaliação externa tenha a mesma intencionalidade formativa e não controladora e seja sensível à multidimensionalidade da realidade humana e à polissemia da educação. 
1 Goldstein e Woodhouse fazem uma primeira aproximação do termo Eficácia Educacional (EEd) por considerarem que o termo Eficácia Escolar (EE) "não é mais uma descrição apropriada da área de pesquisa que lida com instituições além das escolas, e com componentes das escolas tais como salas de aula e outros agrupamentos" (GOLDSTEIN; WOODHOUSE, 2008, p. 423). Essa proposição faz muito sentido, afinal, quando as avaliações educacionais se desvinculam de "qualquer processo meritocrático, cujas restrições foram observadas nesse estudo, confirmando o que já vem sendo apontado há algum tempo em pesquisas internacionais afinal o sucesso ou o fracasso não é da escola ou do professor, tampouco do aluno ou sua família. O sucesso ou - fracasso na educação é do sistema educativo e da própria sociedade que ocorre por meio da escola, do professor, da família e do aluno" (DALBEN, 2014, p. 290)
Para que isso ocorra, a finalidade última da avaliação deve ser garantir que os alunos, independentemente de sua característica social, tenham acesso e permaneçam em escolas com boas condições objetivas, subjetivas e intersubjetivas para que a aprendizagem ocorra de forma semelhante àquela de alunos provindos de famílias com melhor situação socioeconômica. As "escolas seriam vistas como provedoras de igualdade de oportunidades educacionais quando diferentes alunos em diferentes escolas tivessem desempenhos semelhantes" (MADAUS; AIRASIAN; KELLAGHAN, 2008, p. 75).

Como nesse contexto o reflexo do trabalho realizado pelas escolas no resultado obtido é indispensável, torna-se necessária a criação de indicadores que representem tanto o trabalho desenvolvido (indicadores-meio), como os resultados obtidos (indicadores-fim), de modo que os modelos estatísticos auxiliem na análise da eficiência e eficácia dos processos educacionais, gerando importantes informações a serem objetos de análise no processo de avaliação institucional, assim como no delineamento das políticas públicas.

Para os estudos ligados à área da eficácia escolar (que deveria ser eficácia educacional) ${ }^{1}$, o estabelecimento entre variáveis ligadas aos processos (indicadores-meio) e os resultados esperados com esses processos (indicadores-fim) é essencial para a modelagem estatística, embora não se possa perder de vista a complexidade de se pensar em modelagens que permitam a captação dessa multidimensionalidade, assim como as limitações que são inerentes a qualquer quantificação dos fenômenos sociais.

Com o patamar de sofisticação, sensibilidade e robustez tecnológica atingido pelos modelos estatísticos, a melhora de seus resultados depende da qualidade dos dados a eles submetidos, especialmente na forma como são coletados e modelados.

Ao considerar que as medidas necessitam colaborar com os processos avaliativos, não devendo ser vistas como a avaliação das escolas em si, é inevitável levar em conta que, como bem pontua Freitas (2003), a escola é mais complexa do que um conjunto de variáveis a serem manipuladas, o que não quer dizer que os modelos estatísticos não devam 
ser usados, significando simplesmente que eles precisam ser colocados em seu devido lugar.

Claro está que sem medida, não há como avaliar. Necessitamos de evidências concretas para sustentar nossos juízos de valor para que o processo de tomada de decisão possa ser mais consequente. Ninguém pode avaliar de modo puramente intuitivo. Fixar indicadores de qualidade e explicitar critérios que localizem sua presença ou ausência numa dada realidade é questão crucial para a avaliação. (SORDI et al., 2009, p. 43)

Nessa perspectiva, os modelos multidimensionais de avaliação de larga escala associados à avaliação institucional interna à escola certamente abrirão novos horizontes para o trabalho escolar, uma vez que os estabelecimentos escolares não apenas poderão promover o reconhecimento e a complementação dos dados medidos externamente, como serão capazes de gerar dados internos e propor ações que possam garantir a melhoria dos processos vivenciados no cotidiano escolar, rumo a um trabalho que assegure a qualidade social almejada para a garantia do direito à educação constitucionalmente previsto.

\section{CONSIDERAÇÕES FINAIS}

Como exposto neste trabalho, apesar de o uso das medições de larga escala como instrumento de avaliação para fins meritocráticos ser um insolúvel problema, a utilização delas para a composição de uma avaliação mais minuciosa e abrangente do trabalho realizado pela escola é de muita importância se devidamente construída.

O problema a ser perseguido não se restringe aos fatores considerados nesses instrumentos para a avaliação da escola, mas se estende àqueles não considerados quando da elaboração dos instrumentos avaliativos.

Embora já sejam vislumbradas perspectivas mais amplas de avaliação, cujo foco de análise não se limita à mensuração de alguns conteúdos cognitivos complementados por medidas de fluxo e, em desenhos mais arrojados, do nível 
socioeconômico, o mais influente fator na aprendizagem dos alunos, ainda assim permanece o distanciamento de um desenho de avaliação que seja capaz, por um lado, de avaliar o trabalho desenvolvido pelas instituições escolares e, por outro, de servir como auxílio para a melhoria dos processos. Há que se considerar quanto da proficiência adquirida pelo aluno se deve realmente ao trabalho realizado pela escola, assim como identificar outros âmbitos contemplados no cotidiano escolar e também importantes para a formação dos alunos, mas não avaliados pelos testes e não destacados quando os resultados das avaliações em curso são divulgados.

Abarcar esses outros âmbitos constituintes da complexidade do trabalho desenvolvido nas escolas é essencial quando são colocadas em pauta alternativas para a construção de processos de avaliação de larga escala, que exigem não apenas um modelo que considere tal complexidade, como a definição das outras aprendizagens esperadas e importantes na formação dos alunos. Aspecto essencial, mas que exige um trabalho de reconhecimento da escola e de suas atividades ainda não completamente desenvolvido, já que pressupõe a definição do que constitui a qualidade social esperada das escolas e para elas e, no âmbito do processo de avaliação, dos indicadores que poderiam refletir tal qualidade.

Assumir outras dimensões da qualidade para além da aprendizagem em algumas áreas, já medida pelos testes das avaliações em larga escala atualmente em curso, é observar o que ocorre nas escolas e também se constitui como algo importante na formação dos estudantes.

Tal perspectiva superaria, inevitavelmente, as análises unidimensionais, passando a ser reconhecida a característica genuinamente multidimensional do processo educacional e, assim, o necessário desenho de uma avaliação de larga escala multidimensional, que abranja o processo vivenciado no cotidiano escolar trazendo não apenas um retrato da escola, mas informações concretas para que essas instituições possam planejar novos rumos, aprimorando-se constantemente em um processo interno de autoavaliação, não se limitando a dados medidos quantitativamente, já que depende do que é captado qualitativamente. 


\section{REFERÊNCIAS}

ALMEIDA; Luana C. Relação entre o desempenho e o entorno social em escolas municipais de Campinas: a voz dos sujeitos. 2014. 326f. Tese (Doutorado) Universidade Estadual de Campinas, Campinas, 2014.

BETINI, Geraldo A. Avaliação institucional em escolas públicas de ensino fundamental de Campinas. 2009. 394f. Tese (Doutorado) - Universidade Estadual de Campinas, Faculdade de Educação, Campinas, 2009.

CABRITO, Belmiro G. Avaliar a qualidade em educação: Avaliar o quê? Avaliar como? Avaliar para quê?. Cadernos Cedes, Campinas, v. 29, n. 78, p. 178-200, maio/ago. 2009. Disponível em: <www.cedes.unicamp.br>. Acesso em: mar. 2015.

DALBEN, Adilson. Fatores associados à proficiência em leitura e matemática: uma aplicação do modelo linear hierárquico com dados longitudinais do Projeto GERES. 2014. 482 f. Tese (Doutorado) - Universidade Estadual de Campinas, Faculdade de Educação, Campinas, 2014.

DIAS SOBRINHO, José. Campo e caminhos da avaliação: a avaliação da educação superior no Brasil. In: FREITAS, Luiz Carlos de (Org.). Avaliação: construindo o campo e a crítica. Florianópolis: Insular, 2002.

. Avaliação: políticas educacionais e reformas do ensino superior. São Paulo: Cortez, 2003.

FERNANDES, Maria E. A. Avaliação institucional da escola e do sistema educacional: base teórica e construção do projeto. 2. ed. Fortaleza: Demócrito Rocha, 2002.

FREITAS, Luiz C. Ciclos, seriação e avaliação: confronto de lógicas. São Paulo: Moderna, 2003.

Responsabilização, meritocracia e privatização: conseguiremos escapar ao neotecnicismo? In: SEMINÁRIO DE EDUCAÇÃO BRASILEIRA, 3., Centro de Estudos Educação e Sociedade, Campinas, fev. 2011. Disponível em: <www.cedes.unicamp.br/seminario3/luiz_freitas.pdf > . Acesso em: mar. 2015.

GOLDSTEIN, Harvey; WOODHOUSE, Goeffrey. Pesquisa sobre eficácia escolar e políticas educacionais. In: BROOKE, Nigel; SOARES, José F. Pesquisa em eficácia escolar: origem e trajetórias. Belo Horizonte: Editora UFMG, 2008.

HADJI, Charles. Avaliação: a regra do jogo. Tradução de Julia L. Ferreira e José M. Cláudio. Porto: Porto, 1994.

LEITE, Denise. Reformas universitárias: avaliação institucional participativa. Petrópolis: Vozes, 2005.

MADAUS, George F.; AIRASIAN, Peter W.; KELLAGHAN, Thomas. Insumos escolares, processos e recursos. In: BROOKE, Nigel; SOARES, José F. Pesquisa em eficácia escolar: origem e trajetórias. Belo Horizonte: Editora UFMG,

2008. 
SORDI, Mara R. L.; FREITAS, Luiz C. Territórios da medida e da avaliação: elementos para uma avaliação institucional sob medida. In: SORDI, M. R. L.; SOUZA, E. S. S. (Org.). A avaliação institucional como instância mediadora da qualidade da escola pública: a rede municipal de educação de Campinas como espaço de aprendizagem. Campinas: Millennium, 2009.

\section{ADILSON DALBEN}

Professor do Centro Universitário Salesiano de São Paulo (UNISAL), Campus São José, Campinas, São Paulo, Brasil adalben@uol.com.br

\section{LUANA COSTA ALMEIDA}

Professora da Universidade Estadual de Campinas (Unicamp), Campinas, São Paulo, Brasil; e da Universidade do Vale do Sapucaí (Univas), Pouso Alegre, Minas Gerais, Brasil

luanaca@gmail.com 
